\title{
Students create new online resource to support peers
}

Four dental students have come together during the COVID-19 pandemic to create a not-for-profit website called www.revisedental.com. It was created with the aim of helping everyone in the dental profession with their self-directed learning in the fundamental concepts of dentistry.

Dental students Sum, Mike, Leah and Jaini of Revise Dental (pictured) have used the General Dental Council's (GDC's) Preparing for practice learning objectives and an evidence-based approach to provide lessons in the key aspects of the dental degree.

To supplement this, clinicians have been offering support by donating content on their experiences, presentations or

answering student questions from the ReviseDental Community, in order to further student learning. This has been termed 'Premium Content' and encourages students to sign up to the site to enjoy free access to it.

While providing these resources, Revise Dental encourages students and clinicians to donate to the site, in order to raise funds for the BDA Benevolent Fund and the MND Association.

Additionally, to create a community, Revise Dental offers the opportunity for student collaboration. This can be in the form of video teaching, lesson content or sharing student experiences.
This was created to inspire students to share information and knowledge with one-another, particularly in times where group learning is limited. It also encourages students to learn new skills involved in presenting, teaching and teamwork.

Moreover, this area has introduced Inter-Professional Education by involving medical students, pharmacists and nutritionists to create content for the site.

The site has raised $£ 200$ since launching in May, and has received a huge amount of support from across the globe (eg Australia), from both students and clinicians alike. The team has also received support from the British

Dental Students' Association.

Revise Dental team member Sumeet Sandhu said that creating the site 'has been an interesting and character-building exercise, which has allowed the team to learn a variety of skills and understand dental teaching in more depth'.

The site will be beneficial for clinicians, education providers and students to understand the current issues faced by dental students.

'Ultimately, sharing knowledge and encouraging learning will improve and grow the dental profession as a whole, which will benefit patient care and practice,' said Sumeet.

\section{Free access to the Primary Dental Journal}

\footnotetext{
The Faculty of General Dental Practice (FGDP[UK]) is offering non-members free access to the Primary Dental Journal (PDJ) this July.

$P D J$ is the Faculty's quarterly peer-reviewed journal for primary dental care professionals, with three themed issues each year guest-edited by a renowned expert in the field, and one annual general issue covering a wide range of topics. Each issue offers valuable updates relevant to general dental practice, and helps dentists and dental care professionals (DCPs) translate current evidence into best practice.

Normally only available to subscribers and FGDP(UK) Members, online access is free for non-members and nonsubscribers throughout July, without any need to register, at https://journals.sagepub.com/home/prd.

The free access covers not only the current issue, but the entire 20-year online archive of $P D J$ and its predecessor, Primary Dental Care.
}

\section{BDEWF New Writers' Workshop}

Due to continuing uncertainties connected with the pandemic the British Dental Editors and Writers Forum (BDEWF) has decided reluctantly to postpone its annual New Writers' Workshop from this October to 2021. A new date will be publicised as soon as it has been agreed.

\section{Medical emergencies poster included in this issue}

Author Phil Jevon of the Walsall Teaching Academy, Manor Hospital in Walsall publishes a revised and updated version of his article Medical emergencies in the dental practice poster in this issue of the $B D J$ (Volume 229 issue 2, pages 97-104). The poster itself is also included as an insert in the print version of this issue.

The Medical emergencies in the dental practice poster is designed as an aide-memoire to manage medical emergencies in the dental practice and the updated version reflects current national guidelines and recommendations.

This poster, along with Emergency drugs in the dental practice, which is also included as in insert in this issue, can be downloaded from: https:// www.bda.org/advice/Pages/Patient-care.aspx. 